\title{
A constituição de sentido no discurso publicitário sob a perspectiva da semântica argumentativa
}

The meaning constitution in advertising speech from the perspective of the argumentative semantics

\author{
Leyla Ely \\ Alessandra Silveira Bez \\ Angela Derlise Stübe ${ }^{3}$ \\ Universidade Federal da Fronteira Sul, Programa de Pós-Graduação em Estudos Linguísticos. Chapecó, SC, Brasil.
}

Mestranda do Programa de Pós-Graduação em Universidade Federal da (t)

E-mail: leyla.ely@outlook.com

Bacharel em Letras Português-Inglês e PortuguêsFrancês pela UFRGS. Especialista em Estudos kinguisticos pela UFRGS. Mestre e Doutora em etras pela PUCRS.

https://orcid. org/0000-0002-7550-7039

Emall. alessandrasilvierabez@gmail.com

Doutorado em Linguistica Aplicada pela UniverProfessora Doutora da Universidade Federal da Fronteira Sul, Campus Chapecó-SC.

https://orcid. org/0000-0003-1890-5513

E-mail: angelastube@uffs.edu.br
RESUMO: Este artigo analisa a constituição de sentido no gênero publicitário, discutindo-o por meio da Semântica Argumentativa. Para isso verificamos diferentes textos publicitários de épocas distintas à luz da Teoria dos Blocos Semânticos. A seleção do material se deu pelo critério de trabalhar com anúncios dos anos 1960 e 2012/13. As publicidades foram retiradas da internet, com o propósito de relacionar, e discutir linguisticamente, pares de anúncios publicitários de produtos como cigarro, bebida alcoólica e automóvel. Também averiguamos a importância da imagem nos anúncios, discutindo seu valor a partir da leitura de Toldo (2002) sobre a semiótica de Peirce (2000). Já, Carel e Ducrot (2005) fundamentam a teoria central deste trabalho. Os resultados apontam que apesar da equivalência na seleção dos produtos, o significado obtido pelas relações linguísticas constitutivas dos enunciados não são os mesmos, isso porque a especificidade e o propósito de cada publicidade são diferentes. Além disso, conforme os pressupostos teóricos utilizados, a imagem se demonstrou complementar ao discurso verbal, pois o sentido do anúncio é indicado pelo linguístico.

Palavras-chave: Semântica argumentativa; Discurso publicitário; Teoria dos Blocos Semânticos; Relação intralinguística.

ABSTRACT: This paper analyzes the constitution of meaning in the publicity genre, discussing it through Argumentative Semantics. For this, we have checked different advertising texts from distinct periods in light of the Theory of Semantic Blocks. The selection of the material was based on the criterion of working with advertisements from the 1960s and 2012/13. The advertisements were taken on the internet, with the purpose of linguistically relating and discussing advertising pairs of products such as cigarettes, alcoholic beverages and automobiles. We also explore the importance of the image in the ads, discussing its value from the reading of Toldo (2002) on the semiotics of Peirce (2000). Carel and Ducrot (2005) ground the central theory of this research. The results show that despite the equivalence in product selection, the meaning obtained by the constituting linguistic relations of the statements is not the same, because the specificity and the purpose of each advertising are different. In addition, according to the theoretical assumptions used, the image was shown to be complementary to the verb discourse, since the meaning of the advertisement is indicated by the linguistic one.

Keywords: Argumentative semantics; Advertising speech; Semantic Blocks Theory; Intralinguistic relationship 


\section{Introdução}

om a evolução tecnológica e o aumento do consumismo, o gênero publicitário alcançou maior destaque nas sociedades contemporâneas, seu acesso passou a ser amplamente divulgado nas ruas e na mídia, por meio de anúncios impressos e digitais, cartazes, outdoors etc. Seu principal objetivo é convencer, através de enunciados, o público-alvo a comprar determinado produto. Para Rocha e Silva (2007), a publicidade é considerada um fenômeno socioeconômico, no sentido de que é capaz de modificar pontos de vistas e despertar novos desejos ao consumidor.

Quanto à linguagem do gênero, utiliza-se tanto elementos verbais como não verbais, sendo que a imagem auxilia o entendimento do interlocutor sobre o discurso escrito. Para a Semântica Argumentativa, teoria base deste trabalho, o sentido deriva essencialmente das relações intralinguísticas do enunciado, em outras palavras, ele é compreendido pela interdependência semântica da própria língua.

Em nosso estudo, seguimos a visão da Semântica Argumentativa perante a língua e consideramos a imagem como elemento constitutivo do gênero publicitário. Dessa forma, a importância da imagem é discutida segundo a perspectiva de Claudia Toldo (2002) sobre a semiótica de Peirce (2000). Associamos a imagem à explicação de sentido intralinguística de Carel e Ducrot (2005), com base nas relações argumentativas da língua de Ducrot e colaboradores (1990; 2005). Para tanto, a linguagem verbal é chamada de discurso e a linguagem não verbal de imagem, com a clareza de que Toldo (2002) trabalha o discurso como um todo. As discussões sobre gêneros discursivos são pautadas nas contribuições de Mikhail Bakhtin (2011).

Este trabalho é composto por três pares de anúncios dos anos 1960 e 2012/13, em que se procurou manter, para fins de análises, os mesmos produtos, como o cigarro, a bebida alcoólica e o automóvel, e, quando possível, a mesma marca. Os anúncios foram retirados do site "Propagandas Históricas", com o propósito de trabalhar com diferentes épocas. Essa escolha se justifica pelo fato de que, mesmo que a construção de sentido seja apreendida da mesma forma metodológica pela Semântica Argumentativa, discursivamente, a época tem relevância para a compreensão. 0 discurso, na década de 1960, era persuasivo e atingia seu público, nos dias de hoje, entretanto, não é aceitável.

A partir dos anúncios publicitários selecionados, objetivamos mostrar que a Semântica Argumentativa, mais especificamente a Teoria dos Blocos Semânticos, orienta o interlocutor à construção de sentido, tornando-o capaz de identificar a pluralidade de sentido inscrito em cada discurso. Ainda, propomo-nos a observar de que forma a imagem contribui para o entendimento do enunciado e se o período de publicação dos anúncios influencia ou não o sentido estabelecido intralinguisticamente.

Para iniciar o percurso teórico, exploremos a definição de gênero do discurso, bem como suas principais características.

\section{Gêneros do discurso}

Conforme Bakhtin (2011), os gêneros do discurso são denominados pelo campo de utilização da língua, nos quais são elaborados seus tipos relativamente estáveis de enunciados. Essa estabilidade é influenciada pela história e pelas marcas sociais do locutor, sendo o enunciado particular e individual.

O enunciado é formado e ligado pelo conteúdo temático, o estilo e a construção composicional (cf. BAKHTIN, 2011). 0 primeiro faz referência aos vários temas abordados em um gênero, como o humor, a ironia e o drama; o 
segundo está ligado ao estilo de quem escreve, ou seja, às particularidades e singularidade do autor; e o terceiro trata da estrutura interna geral do enunciado, que se organiza conforme o gênero discursivo. Na publicidade, por exemplo, o tema varia de acordo com os objetivos do anúncio, entre eles podemos citar o de prevenção - quando o locutor alerta o interlocutor contra algo ou alguém -, ou de transmissão de uma mensagem por meio de artifícios linguísticos, como a ironia. A publicidade também costuma apresentar uma mensagem breve, uma gramática simplificada e um padrão de estrutura, como a utilização da logo-marca e o uso da linguagem verbal e não verbal.

Na concepção de Bakhtin (2011), os gêneros do discurso se dividem em duas categorias: os primários e os secundários. Os gêneros primários são representados pela comunicação informal, incorporado pelo discurso oral ou escrito do dia a dia, alguns exemplos são: diálogos, bate-papo, cartas privadas e bilhetes. Por sua vez, os gêneros secundários, chamados de complexos, apresentam um grau elevado de formalidade, pelo fato de seu discurso requerer maior elaboração, como é o caso de pesquisas científicas e documentos de lei.

Ainda, o enunciado se difere pela natureza linguística - oral ou escrita e pelos distintos campos da atividade humana e da comunicação. Segundo Bakhtin (2011), cada gênero discursivo demanda certo tipo de atividade, como um documento de lei, em que há uma regularidade na organização do texto e uma formalidade maior na escrita, o que não ocorre, por exemplo, em um texto literário, pois somente este pode ser marcado pela individualidade do sujeito falante. Essa ocorrência ou não da marca do sujeito é vinculada à linguagem e se materializa na forma individual, fazendo com que o enunciado se torne particular e se relacione com a língua nacional (nível do léxico e da gramática).

A explanação feita sobre gêneros discursivos é importante para a compreensão das particularidades do gênero publicitário e para, mais adiante, relacionarmos com o corpus do trabalho. Para tanto, seguimos com a discussão sobre imagem e discurso verbal.

\section{Uma releitura sobre semiótica de Peirce}

Toldo (2002), em seu trabalho, propõe uma releitura da semiótica apresentada por Peirce (2000), no qual explica a relação entre o discurso verbal e o não verbal como uma forma de argumentação, sendo que a imagem exemplifica o sentido produzido no enunciado. A autora apresenta alguns conceitos estudados por Peirce (2000) e, assim, relaciona a significação da imagem com o sentido produzido pelo discurso verbal.

Para ambos estudiosos, a imagem é vista como um signo, que está no lugar de alguma coisa para alguém, em uma relação ou uma qualidade. 0 signo, segundo Toldo (2002), é separado em três tipos: os ícones, os índices e os símbolos. O ícone é aquele signo que corresponde ao significante que mantém uma relação com o referente; o índice é aquele que está em uma relação com o que representa; e o símbolo corresponde à relação de convenção com o seu referente.

Da mesma forma, os autores propõem três possíveis modalidades de compreender todo e qualquer fenômeno, a saber: a primeiridade, que se refere ao modo mais imediato, forma rudimentar de prédica das coisas; a secundidade, que possui relação de dependência entre dois termos; e a terceiridade, a qual aproxima por meio de uma síntese intelectual um primeiro e um segundo, é uma elaboração cognitiva (cf. TOLDO, 2002, p. 152).

Ademais, Toldo (2002) afirma que a imagem, quando posta ao lado do texto verbal, produz relações de sentido que juntas argumentam. Em outras palavras, a imagem posta ao lado do discurso verbal faz com que o propósito do enunciado se torne mais completo, além de permitir 
ao interlocutor novas possibilidades de interpretações e produções de sentido.

Compreendendo o valor da imagem para a constituição de sentido e percebendo-a como elemento constitutivo do gênero publicitário, apresentamos, a seguir, a Teoria dos Blocos Semânticos.

\section{Teoria dos Blocos Semânticos}

A Teoria dos Blocos Semânticos (TBS), desenvolvida por Carel e Ducrot (2005), mantém as bases teóricas da Teoria da Argumentação na Língua (ANL), pois entende que o sentido é elaborado pelas relações intralinguísticas e não por fatores externos à língua. A TBS, no entanto, se desenvolveu no sentido de perceber que a argumentação decorre da relação dos encadeamentos argumentativos do tipo normativo e do tipo transgressivo.

Segundo Carel e Ducrot (2005), os conectores normativos e transgressivos servem para unir dois segmentos chamados de aporte e suporte. A junção desses dois segmentos produz uma interdependência semântica que gera sentido, pois se os segmentos forem considerados separadamente, o sentido do enunciado não é concluído. A representação dos conectores normativos, aqui formalizados pelo "portanto" (DC) ${ }^{1}$, e dos conectores transgressivos, equivalentes ao "no entanto" $(\mathrm{PT})^{2}$, podem ser substituídos por outras palavras cuja carga semântica seja a mesma, como: então, assim, logo (normativos), e porém, mas (transgressivos). Em nosso trabalho, utilizamos as representações dos conectores "portanto" e "no entanto".

${ }^{1}$ DT $=$ donc em francês e "portanto" em português.

2 PT = pourtant em francês e "no entanto" em português.
Ainda sobre o aporte e o suporte de um enunciado (ou seja, o segmento consequente e o antecedente), Carel e Ducrot (2005) enfatizam que eles são demarcados independentemente de sua ordem ou de sua posição em um enunciado. Em um exemplo como "vai chover, não vamos passear", tem-se o mesmo suporte em "não vamos passear, irá chover", mesmo que sua ordem seja trocada. Assim, o que depende de ir passear é a causa chuva e não o contrário, tem-se, portanto, a chuva como suporte de ir passear.

Para compreendermos as relações argumentativas a partir dos conectores normativos e transgressivos, citados anteriormente, tomamos como exemplo:

(1) Ele trata as pessoas bem, portanto é bom.

(2) Ele trata as pessoas bem, no entanto não é bom.

Em (1), o argumento "tratar as pessoas bem" desencadeia o sentido de "ser bom", representado através do encadeamento normativo "tratar bem DC bondade", ao passo que em (2), encontramos o encadeamento transgressivo, em que o primeiro segmento "tratar as pessoas bem" remete a outro sentido, o de "não ser bom", demonstrado pela relação argumentativa de "tratar bem PT neg-bondade". Os exemplos (1) e (2) possuem uma interdependência semântica, que conduz a uma relação argumentativa e produz sentido.

Logo, os encadeamentos (1) e (2) refletem a relação conversa, vista no Bloco Semântico gerado pelos segmentos "tratar bem e ser bom". O Bloco Semântico é apresentado pelos teóricos Carel e Ducrot (2005) para comprovar que o sentido é compreendido a partir das relações argumentativas e pelas instruções do próprio sistema linguístico, representado nas Figuras 1 e 2: 
Figura 1 - Bloco Semântico 1

Bloco semântico 1

(1) A PT neg - B

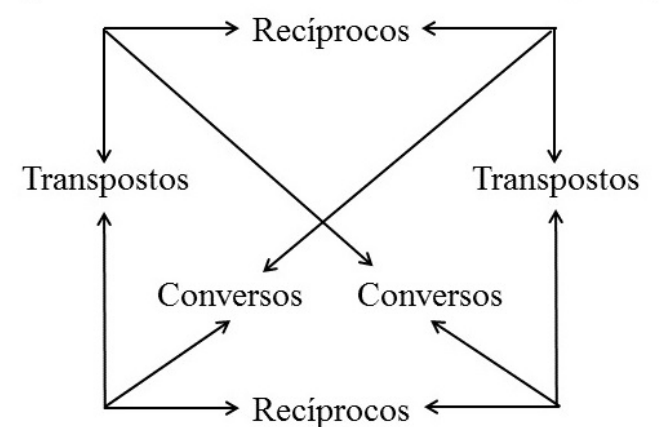

(3) neg - A DC neg - B

(4) A DC B

Fonte: Adaptado de Carel e Ducrot (2005, p. 46)

Figura 2 - Bloco Semântico 2

\section{Bloco semântico 2}

(5) A PT B

(6) neg - A PT neg - B

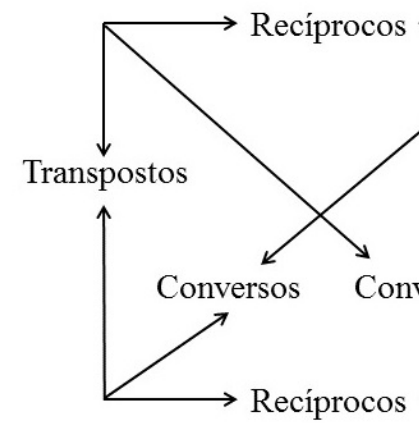

(7) neg - A DC B

(8) A DC neg - B
Bloco Semântico 1 (BS1)

(1) A PORTANTO B = "Tratar bem DC ser bondoso"

(2) A NO ENTANTO NEG-B = "tratar bem PT não ser bondoso"

(3) NEG-A NO ENTANTO B = "Não tratar bem PT ser bondoso"

(4) NEG-A PORTANTO NEG-B = "Não tratar bem DC não ser bondoso"

Bloco Semântico 2 (BS2)

(5) A PORTANTO NEG-B = "Tratar bem DC não ser bondoso"

(6) A NO ENTANTO B = "Tratar bem PT ser bondoso"

(7) NEG-A PORTANTO B = "Não tratar bem DC ser bondoso"

(8) NEG-A NO ENTANTO NEG-B = "Não tratar bem PT não ser bondoso"

A interdependência semântica entre os segmentos que produzem os encadeamentos argumentativos resulta em oito sentidos capazes de expressar um enunciado, denominados de aspectos argumentativos, dos quais quatro são determinados pelo BS1 e outros quatro pelo BS2. Com base na TBS, a argumentação está inserida na relação dos encadeamentos argumentativos que nos leva a um sentido. Tais relações são vistas de maneira mais precisa na seção análise e discussão dos resultados, a seguir.

\section{Análise e discussão dos resultados}

Para compor o corpus de nosso trabalho, selecionamos três pares de anúncios dos anos 1960 e 2012/13. A partir disso, analisamos como o sentido é constituído nos discursos publicitários de diferentes épocas, conforme as marcas intralinguísticas do enunciado, da mesma forma que relacionamos o sentido com a importância da imagem nos anúncios. $\mathrm{O}$ valor da imagem (elemento não verbal) é abordado de acordo com o trabalho de Toldo (2002), e o discurso (linguagem verbal) é debatido com base em Carel e Ducrot (2005).

Fonte: Adaptado de Carel e Ducrot (2005, p. 46). 
O primeiro anúncio publicitário é de 1967 e tinha como objetivo a venda da cerveja Malzbier da Brahma (Figura 3).

Figura 3 - Anúncio publicitário da cerveja Brahma, ano 1960

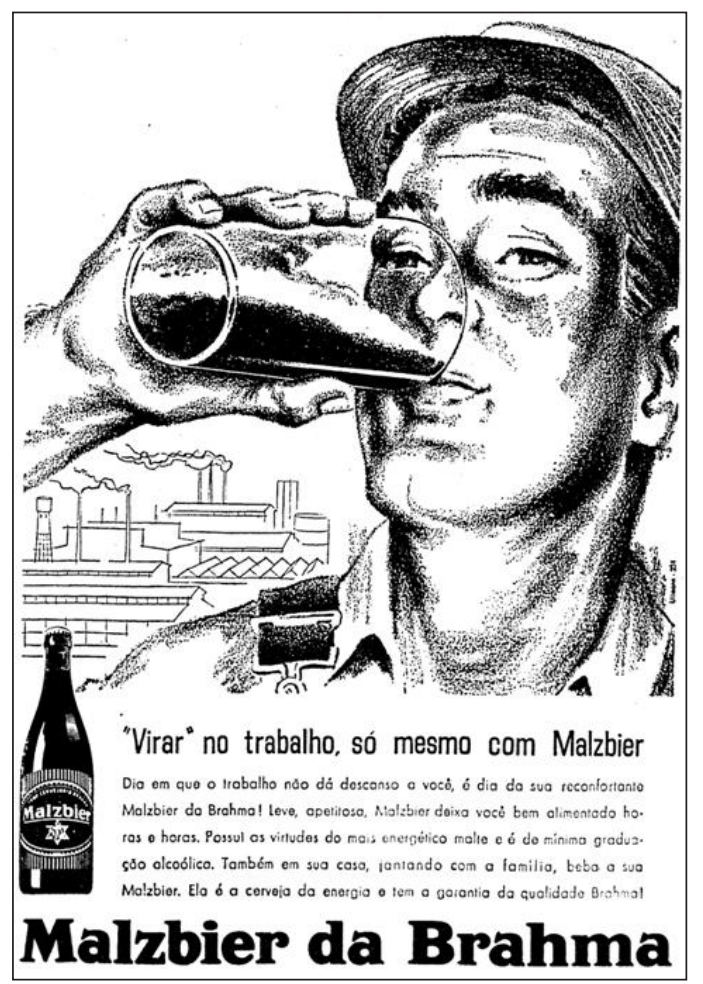

Fonte: <http://www.propagandashistoricas.com.br/2013/09/ cerveja-malzbier-beber-no-trabalho-1967.html>.

O primeiro anúncio publicitário apresentado se refere à propaganda dos anos 1960 da marca Brahma, que objetivava vender a cerveja tipo Malzbier ao público da classe trabalhadora da época. 0 anúncio exibe o seguinte enunciado principal: "'Virar' no trabalho, só mesmo com Malzbier". Nesse discurso, podemos notar o uso da ambiguidade sobre o item lexical "virar"3, propiciando dois sentidos emergentes: o primeiro diz respeito à condição do operário/empregado virar no trabalho, ou melhor, o operário só consegue virar o dia trabalhando se tomar Malzbier da Brahma - sentido esse demarcado pelo discurso e pela carga semântica concedida a "só mesmo"; o segundo sentido de "virar" está relacionado ao fato de virar literalmente o copo de Malzbier, bebendo toda cerveja - indicação essa instruída pelo linguístico, e compreendida pela imagem. Destacamos, via TBS, o primeiro entendimento possível:

A DC neg B - Virar no trabalho, portanto não ter energia.

A PT B - Virar no trabalho, no entanto ter energia com Malzbier.

Nessa relação de sentido, conduzida pelo encadeamento argumentativo, há uma conversão, demarcada pelo BS2 (Fig. 2), em que o primeiro encadeamento é composto por neg energia e o segundo pela afirmação de que para "virar no trabalho" e ter energia há a necessidade de tomar a cerveja Malzbier da Brahma. Para chegarmos a tal conclusão, verificamos, inicialmente, as relações estabelecidas entre os enunciados e, após, buscamos compreender as relações dos encadeamentos argumentativos que nos conduzem ao sentido.

O discurso do enunciado nos permite constatar que, primeiramente, o trabalho é visto como algo cansativo e, portanto, "virar no trabalho" se torna uma realização árdua e difícil de ser executada, pois o trabalhador não tem energia e/ou forças suficientes para exercer tal tarefa. Essa primeira relação desencadeia outra afirmação que mantém o sentido de que "virar no trabalho" é uma tarefa difícil, mas é possível de realizá-la. Para "virar no trabalho", no entanto, é preciso tomar a cerveja Malzbier da Brahma, dado que ela é fonte de energia e torna as horas a mais de trabalho

3 Sempre que referenciamos alguma palavra, frase ou discurso retirado do enunciado, utilizaremos a grafia itálica para destacar tal fragmento. 
possíveis de serem cumpridas e superáveis ao esforço do operário. Com o uso do conector "só mesmo", no enunciado, a cerveja Malzbier se torna um diferencial, haja vista que o peso semântico da palavra "só mesmo" atribui à Brahma a responsabilidade de ser a única marca/cerveja com o poder de fazer o trabalhador "virar no trabalho".

Outro elemento fundamental a ser explanado é a significação da imagem no anúncio publicitário. Na perspectiva de Toldo (2002), a imagem e os elementos que a constituem são significativos para o enunciado e para a pretensão de sentido que se quer gerar. Segundo Toldo (2002, p. 157), "os índices colocam-se na representação de objetos que o indivíduo que os vê relaciona", no caso do anúncio da cerveja Malzbier, o índice composto pelo ambiente de trabalho está relacionado ao operário e ao fato de ele estar virando o copo de cerveja para ir trabalhar. Já os ícones (o copo, a cerveja e o trabalhador) conduzem o interlocutor ao segundo sentido desencadeado pelo item lexical "virar", cuja indicação inicial se encontra no linguístico.

A seguir, analisamos outro anúncio da cerveja Brahma (Figura 4). A propaganda publicitária é de 2012 e também faz alusão ao trabalhador.

Figura 4 - Anúncio publicitário da cerveja Brahma, 2012.

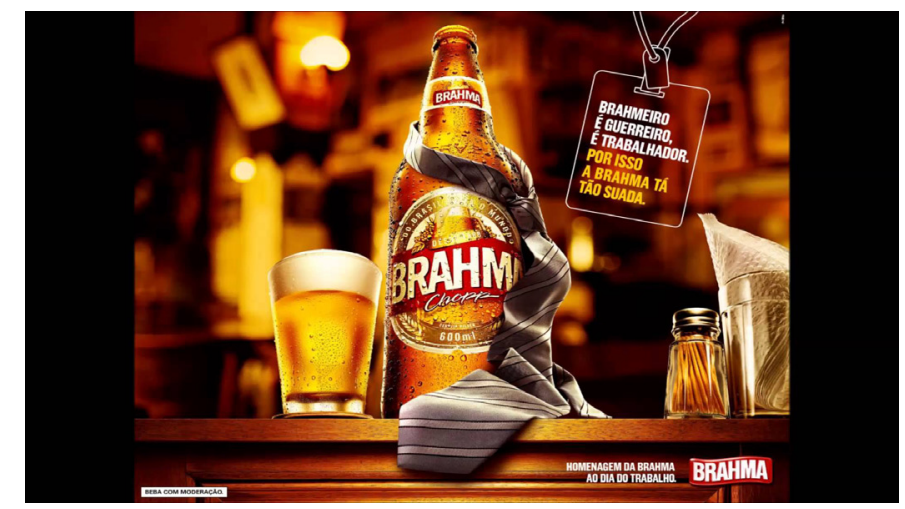

Fonte: <http://tudibao.com.br/2012/05/dia-do-trabalho-e-trabalhador.html>.
Nesse anúncio, a Brahma faz uma homenagem ao dia do trabalhador: "Brahmeiro é guerreiro, é trabalhador, por isso a Brahma tá tão suada". Ao compararmos ambas publicidades, percebemos uma diferença no propósito discursivo, que consiste em, nos anos 1960, a cerveja Brahma estar associada à fonte de energia e seu consumo ser incentivado durante o trabalho, e, atualmente, ser inspiração para concluir essas horas. A cerveja Brahma, no ano de 2012, está associada à comemoração após a jornada de trabalho, como se fosse um prêmio ou uma gratificação a quem passou o dia trabalhando.

Temos, via TBS, a seguinte relação proposta pelos encadeamentos argumentativos:

A DC B - Ser guerreiro e trabalhador, portanto ser brahmeiro.

A DC B - Ser brahmeiro, portanto tomar Brahma.

O sentido do discurso verbal está contido na relação de que para beber a cerveja Brahma deve-se ser brahmeiro. Ser guerreiro e ser trabalhador equivale a ser brahmeiro, pois no primeiro encadeamento argumentativo, a interdependência semântica está em "todo brahmeiro é trabalhador e guerreiro". Nesse sentido, a cerveja Brahma se iguala aos trabalhadores, seu suor é representado pelo suor de quem trabalha, ou seja, do trabalhador guerreiro, merecedor da Brahma.

Além do suor, outras marcas que reafirmam esse discurso são postas na imagem da publicidade, como a gravata e o crachá. A relação entre o discurso verbal e o não verbal se mostra importante, pois é por meio dessa relação que, conforme Toldo (2002), ocorre a compreensão efetiva do sentido do enunciado e faz com que a argumentação seja mais consistente. As indicações não verbais, como os ícones, índice e símbolos desse anúncio são complementares para a constituição de sentido. A gravata colocada 
no "pescoço" da cerveja e o enunciado escrito dentro de um crachá de identificação do trabalhador frisam o valor da imagem no anúncio publicitário, assim como o ambiente, representado pelo índice bar, e a cerveja, que apontam ao interlocutor que este é um propício fim de tarde, depois de um longo e cansativo dia de trabalho.

Ainda sobre a representatividade da gravata, destacamos que, com ela, há uma restrição à homenagem designada ao trabalhador, uma vez que, segundo o anúncio, o verdadeiro brahmeiro é aquele indivíduo que usa gravata em sua atividade profissional ou aquele que possui crachá de identificação. A partir da imagem, concluímos que o discurso de "quem merece tomar Brahma é quem é guerreiro e trabalhador, portanto brahmeiro" se refere aos trabalhadores engravatados.

Na homenagem que a Brahma faz ao trabalhador, a cerveja está como reflexo do Brahmeiro e como sinônimo de conquistas, distintamente da publicidade antiga, em que a cerveja era uma energia a mais para a pessoa continuar trabalhando, bebendo-a no próprio local de trabalho. Essa discrepância entre ambos os discursos da Brahma é ocasionada pelo passar dos anos. Os discursos são produzidos de acordo com a situação enunciativa e conforme quem é o interlocutor, uma vez que hoje o discurso dos anos 1960 não seria mais pertinente. Também, observamos uma diferença no públicoalvo das publicidades, pois, nos anos anteriores, a Brahma tencionava alcançar os operários e, na atualidade, o alvo passa a ser os trabalhadores engravatados, visto que não é o operário, pedreiro ou o diarista que usa gravata para trabalhar.

A seguir, apresentamos outro par de anúncios. Ambos têm como tema principal o cigarro, entretanto, o primeiro anúncio incentiva o consumo de tabaco com o objetivo de vender um cachimbo (Figura 5), e o segundo busca prevenir e alertar sobre o consumo de cigarro.
Figura 5 - Anúncio publicitário cachimbo Bulldog, 1969.

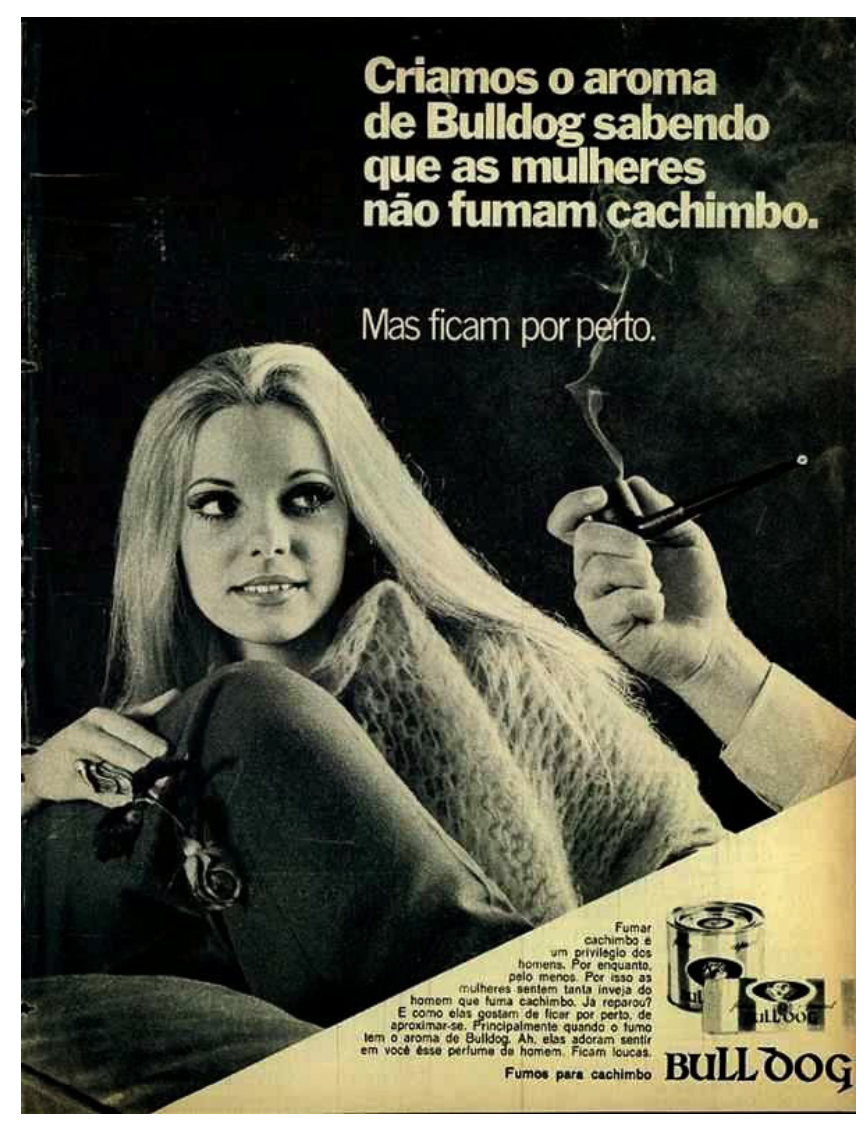

Fonte: <www.propagandashistoricas.com.br/2015/01/cachimbo-bull-dog mulheres-por-perto.html>.

Nesse anúncio publicitário, o produto de venda é o cachimbo Bulldog, o qual está aparentemente ligado à mulher. No enunciado: “Criamos o aroma de Bulldog sabendo que as mulheres não fumam cachimbo. Mas ficam por perto", confirmamos a relação do ato de fumar com a imagem da mulher. 


\section{Via TBS, temos:}

A DC B - Cachimbo com aroma Bulldog, portanto mulheres por perto.

Neg A DC Neg B - Cachimbo sem aroma Bulldog, portanto sem mulheres por perto.

Nesse encadeamento argumentativo, a interdependência semântica resulta na dependência de "mulheres por perto" com o "aroma Bulldog", visto que esse aroma é o motivo que atrai as mulheres e as deixam por perto.

A relação dos encadeamentos é de reciprocidade, visto no BS1 (Fig. 1), já que o sentido do discurso é mantido, isto é, no primeiro encadeamento, temos a causa de as mulheres ficarem por perto (no caso o aroma Bulldog do cachimbo) e, no outro, o motivo de elas não permanecerem por perto, ou seja, sem o aroma Bulldog as mulheres não ficam por perto. 0 "aroma Bulldog" está relacionado ao cheiro do homem, sendo este um motivo para as mulheres se relacionarem com o sexo oposto.

A imagem, ao complementar o enunciado discutido linguisticamente, se mostra como forte argumento, afirmando o sentido produzido pelo discurso verbal. Ou seja, a imagem da mulher ajoelhada/deitada entre as pernas de um homem, segurando uma flor e olhando para o parceiro, como se o admirasse, enquanto ele fuma seu cachimbo, vai ao encontro das relações intralinguísticas que mostram a finalidade do anúncio em cativar e convencer o público masculino. Esses argumentos são utilizados, pela referida publicidade, para engrandecer a masculinidade do homem e, assim, causar uma aproximação entre o produto e seu consumidor.

Discutido o sentido do anúncio dos anos 1960, dispomos, a seguir, de uma publicidade atual, em que o uso do cigarro é visto como algo preocupante à saúde. Na Figura 6, um alerta sobre o risco à saúde de quem fuma.
Figura 6 - Campanha publicitária de combate ao cigarro, 2012.

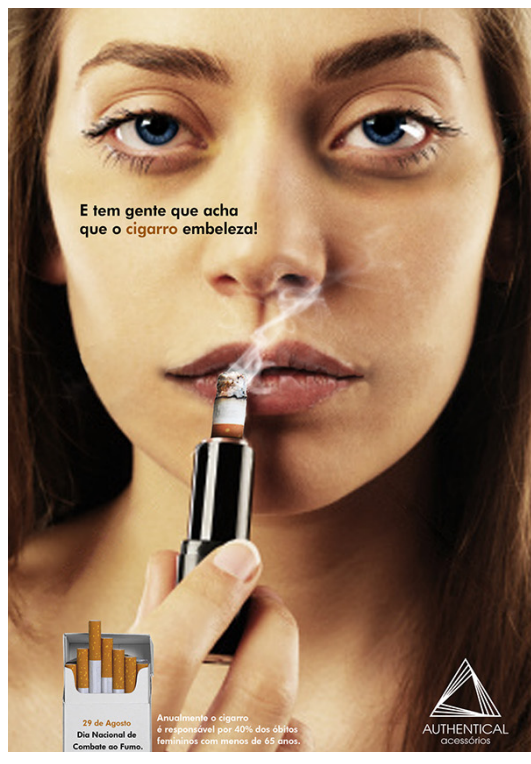

Fonte: <www.behance.net/gallery/4567555/ Dia-Nacional-de-Combate-ao-Fumo>

Esse anúncio apresenta um discurso que visa à prevenção do consumo de cigarro. 0 enunciado principal dispõe o seguinte discurso verbal: "E tem gente que acha que o cigarro embeleza!", demostrando o ponto de vista do locutor. A partir do enunciado, temos os seguintes pontos de vista: "beleza, portanto fumar", e negado pelo locutor na segunda relação encadeada por: "beleza, no entanto não fumar", sendo que o que está em questão neste anúncio é se o cigarro é ou não motivo de beleza. Conforme TBS:

A DC B - Ter beleza, portanto, fumar cigarro.

A PT Neg-B - Ter beleza, no entanto não fumar cigarro. 
Nessa relação intralinguística, verificamos que há uma relação conversa. Em A DC B apresenta-se o sentido evocado linguisticamente, já que fumar é associado à beleza, sendo desfeito pelo encadeamento argumentativo A PT Neg-B.

O sentido do anúncio publicitário, portanto, está na polifonia empregada em que ainda há pessoas que pensam que fumar é motivo de beleza, quando na realidade não é. As marcas e as relações intralinguísticas deixam clara essa percepção, uma vez que ainda há pessoas que pensam que fumar é sinônimo de beleza, apesar de que todos os outros argumentos negam tal afirmação, inclusive a imagem, exposta na publicidade. A mulher, que está "se embelezando", reafirma esse posicionamento, pois o batom utilizado pela mulher é, na verdade, a ponta de um cigarro aceso.

A noção de que fumar causa beleza é desfeita quando o rosto da mulher é analisado, pois nele percebe-se um olhar cansado, causado pelo cigarro e pela inalação da fumaça tóxica. Na referida publicidade, o ícone batom é fundamental para o valor de beleza e o cigarro para o entendimento contrário.

Ao compararmos as publicidades sobre o consumo de cigarro, notamos que esta elabora seu discurso numa perspectiva totalmente distinta. 0 anúncio desfruta de elementos linguísticos para fazer o interlocutor refletir sobre os malefícios do cigarro. Dessa forma, o locutor consegue fazer o interlocutor perceber que o cigarro é um risco à saúde, conscientizando e alertando sobre os danos do tabaco e de seu consumo ao organismo. Já o discurso dos anos 1960, além de incentivar o consumo, mostra a superioridade do homem e desqualifica a mulher, fazendo dela um objeto de uso e um incentivo para o homem querer fumar.

Em ambas as publicidades, a mulher está como um instrumento importante para o convencimento do consumidor, porém, uma retrata a mulher de maneira inferior, e outra exibe sua imagem para mostrar o quanto o cigarro e as substâncias tóxicas nele contidas são prejudiciais e inferiorizam a imagem da mulher, mesmo que em um primeiro momento possa parecer um instrumento de beleza. Há, assim, um claro contraste nos discursos (verbais e não verbais), já que no anúncio mais antigo, fumar era algo prazeroso e elevava a autoestima do fumante, ao passo que nos anos atuais, afirmar que fumar é algo bonito e grandioso se torna uma ironia posta a quem não reconhece o quanto o cigarro faz mal às pessoas e ao organismo.

Passemos ao último par de anúncios publicitários. A Figura 7 corresponde à publicidade da Volkswagen de 1960.

Figura 7 - Anúncio publicitário do automóvel Fusca da Volkswagen, anos 60.

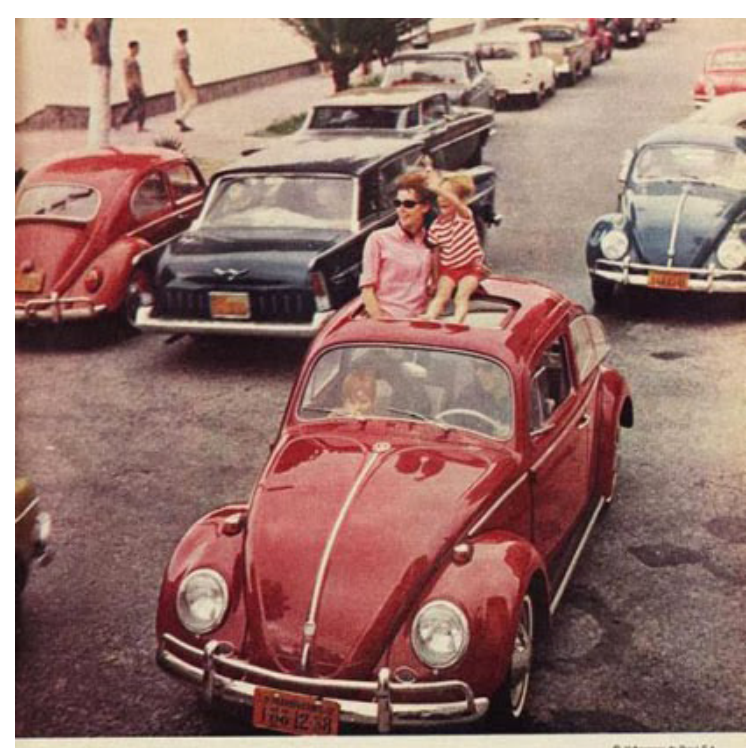

Nova (e arejada) maneira de passear.

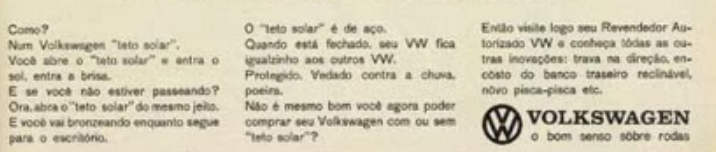

Fonte: <www.propagandashistoricas.com.br/2014/02/ volkswagen-fusca-conversivel-anos-60.html> 
Nessa publicidade, o discurso principal é: “Nova (e arejada) maneira de passear", em que se infere, pela articulação do discurso com a imagem, que, anteriormente, as pessoas passeavam com seus automóveis de um jeito comum e, agora, há uma nova maneira, compreendida, especificamente, quando referenciada à imagem ou ao texto complementar. 0 sentido construído via TBS é:

A DC B - Fusca com teto solar, portanto, nova forma de passear.

Neg A DC Neg B - Fusca sem teto solar, portanto velha e não arejada maneira de passear.

A relação recíproca demarca que há uma nova maneira de passear, visto que, anteriormente, o carro não era arejado e o passeio se tornava comum. O sentido, construído pela relação dos encadeamentos argumentativos, é de que para se passear com essa nova e arejada maneira é preciso ter o novo Fusca com teto solar. Contudo, o discurso principal limita o interlocutor ao entendimento superficial do anúncio, ocultando a informação detalhada de como é essa nova e arejada maneira de passear.

O item lexical "arejada" está posto como um discurso complementar, em que há uma informação vista como não completa ou não clara, pois para o entendimento exato do enunciado é preciso recorrer a mais um recurso, nesse caso, o texto que especifica a venda do carro ou a imagem, que também integra o sentido do anúncio.

Novamente, a imagem, vinculada ao slogan da publicidade, facilita o entendimento proposto ao interlocutor. A imagem, representada pelo fusca e pelas pessoas passeando de uma nova e arejada maneira, argumenta a favor do enunciado, reiterando o objetivo do anúncio, bem como mostra ao interlocutor que é possível passear conforme o convite realizado no discurso. Assim, ao recorrermos à imagem e sua representatividade, identificamos que passear de forma arejada é passear com o Fusca teto solar.
Um carro com teto solar propicia um passeio diferente, pois além de poder abrir o teto solar, os passageiros do Fusca têm o privilégio de apanhar um vento e ainda ver a paisagem enquanto alguém dirige. Essas possibilidades são mostradas na cena do anúncio publicitário, representadas pelo homem dentro do Fusca e pela criança sentada em cima do automóvel, prontos para dar um passeio. Há, por sua vez, outro homem, que está a conduzir o Fusca e a levar os passageiros para passear. Esses argumentos certificam o valor que a imagem tem para semantizar o que o locutor enuncia para seu interlocutor no discurso verbal.

Observemos os contrastes da publicidade do ano de 2013 (Figura 8):

Figura 8 - Anúncio publicitário do Novo Fusca da Volkswagen, 2013.

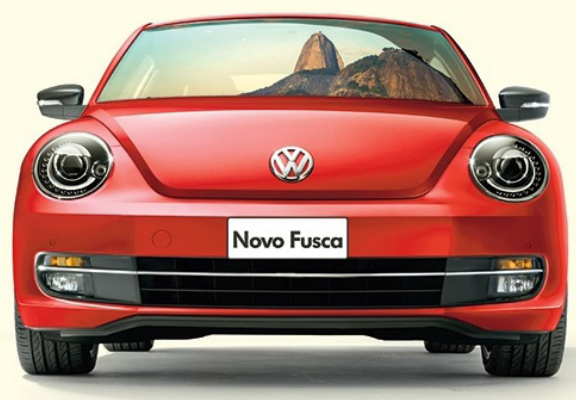

O Ria de Janeino continwa winda Graças a vocế, que vem nas 5 concessionárias da Recreio fechar o melhor negócio,
a gente é lider no Brasil, ano após ano, hà quase 20 anos. A vocé o nosso muito obrigado.

\section{(ब) Recreio}


De acordo com o anúncio do Novo Fusca publicado no ano de 2013, o enunciado principal é: "O Rio de Janeiro continua vindo". Via TBS, compreende-se o sentido da seguinte maneira:

A DC B - Ter Novo Fusca, portanto, chegar aonde você quiser.

Neg-A DC Neg-B -- Não ter Novo Fusca, portanto, não chegar aonde você.

A relação entre os segmentos incute o sentido de que o enunciado "O Rio de Janeiro continua vindo" é o destino desejado aonde o interlocutor quer chegar, uma vez que o Novo Fusca o conduzirá até a cidade de Rio de Janeiro (portanto, ela está indo ao seu encontro). Como o Rio de Janeiro está associado ao destino, concluímos, pela relação intralinguística, que o Novo Fusca é o meio que levará o interlocutor a chegar aonde ele quiser, sendo que sem o Novo Fusca não se chega aonde se quer, havendo uma relação de reciprocidade estabelecida pelos encadeamentos argumentativos.

Compreendemos que a cidade do Rio de Janeiro é o destino, porque, além do que está inscrito no discurso verbal, a cidade está projetada no para-brisa do Fusca, como se o Rio de Janeiro continuasse vindo, como se ele estivesse se aproximando do condutor do Fusca, ou como se fosse o próprio Pão de Açúcar o condutor do carro, levando em consideração que a imagem vista pode estar atrás do para-brisa e não projetada nele. Além disso, o enunciado principal apresenta uma polifonia e nos remete a música "Aquele abraço" de Gilberto Gil, em que há um trecho relacionado ao que está na propaganda da Volkswagen "O Rio de Janeiro continua lindo", letra da música brasileira que lembra a cidade litorânea.

Quando analisamos o discurso complementar, percebemos que o anúncio publicitário também é um agradecimento ao Carioca que continua comprando os automóveis Volkswagen na concessionária Recreio, tornando-a líder no mercado automotivo brasileiro.
Nesse caso, se compararmos a publicidade atual com a antiga, podemos notar que não há uma divergência entre os argumentos, já que o objetivo é a venda do Novo Fusca, mostrando suas prioridades em ambas as propagandas. Já nos pares de anúncios publicitários anteriores (cerveja e cigarro), há uma disparidade nos argumentos produzidos pelo locutor, que são estabelecidos pelas marcadas intralinguísticas do enunciado. Num primeiro momento, as relações ocorrem pela associação da bebida alcoólica como fonte de energia, o cigarro como demonstração da virilidade do homem e o automóvel como uma nova forma de passear. Num segundo momento, tais relações mudam na medida em que a bebida alcoólica passa a ser motivo de comemoração e conquista, o cigarro se transforma em uma razão para a prevenção do seu consumo, e o automóvel se torna uma justificativa para o agradecimento aos Cariocas que compram na concessionária Recreio.

Desse modo, realizadas as análises, constatamos que, apesar da equivalência entre as marcas e os temas apresentados, os discursos publicitários possuem uma diferença em seus argumentos, ocasionada pelo objetivo e pelo propósito da propaganda. Averiguamos tais fatos pelas instruções e relações intralinguísticas dos diferentes anúncios, sendo os discursos construídos conforme a época em que cada anúncio foi criado, por exemplo, no caso da propaganda do cachimbo Bulldog, que há uma relação entre fumar Bulldog e ter mulheres por perto, utilizando a imagem da mulher de forma depreciativa para o convencimento do interlocutor à compra, distantemente da propaganda atual, que se posiciona contra o consumo de cigarro.

Destacamos, igualmente, a pluralidade de sentido encontrada nos anúncios, justificada pela relação do discurso verbal e não verbal. Ao recorrer às imagens, um segundo sentido é confirmado, sentido esse previsto anteriormente pelo linguístico. A imagem auxilia o entendimento da publicidade e está em uma relação de argumentação com o discurso 
verbal, como no caso da cerveja Malzbier da Brahma, em que o discurso não verbal facilita a compreensão do segundo sentido causado pela ambiguidade do item lexical "virar".

Essas constatações mostram que a imagem não apresenta um sentido novo, um sentido que não estivesse instruído pelo linguístico, mas que é um meio de ilustrar o sentido contido no enunciado, reforçando e direcionando a argumentação da propaganda. Ou seja, a imagem, juntamente com o contexto intralinguístico, recupera a semanticidade, sendo que o material linguístico indica como chegar à construção de sentido no discurso a partir do que a língua oferece nos enunciados.

\section{Considerações finais}

Com este trabalho, possibilitamos ao leitor uma visão puramente linguística para a compreensão de sentido dos anúncios publicitários. Os resultados alcançados são de que o modo com que a Teoria dos Blocos Semânticos (TBS) propõe a constituição de sentido leva o interlocutor a compreender as relações linguísticas e o sentido do enunciado. Constatamos, ainda, que a TBS não descarta outros elementos que possam contribuir para esse entendimento, como o uso da imagem que é constitutiva do gênero publicitário.

Quanto aos temas das publicidades, abordados nas análises e discussões dos resultados, são verdadeiramente instigantes e debatidos na sociedade nos dias de hoje, o que possibilita outras visões perante o discurso, como a discussão sobre a ideologia do politicamente correto (que aqui não nos coube, já que adotamos um olhar estritamente linguístico). Sugerimos, a futuros trabalhos, que o discurso complementar dos anúncios publicitários também seja analisado, uma vez que o texto secundário apresenta informações detalhadas sobre a descrição e venda do produto, requerendo, assim, um trabalho mais extenso, que pode (ou não) seguir esta mesma linha de pesquisa.

\section{Referências}

ANSCOMBRE, Jean-Claude; DUCROT, Oswald. L'argumentation dans la langue. Paris: Mardaga, 1983.

BAKHTIN, Mikhail. Os gêneros do discurso. In: BAKHTIN, Mikhail. Estética da Criação Verbal. 6. ed. São Paulo: WMF Martins Fontes, 2011. p. 277-289.

CAREL, Marion; DUCROT, Oswald. La Semántica Argumentativa. Una Introducción a la Teoría de los Bloques Semánticos. Edición literaria a cargo de María Marta Negroni y Alfredo M. Lescano. Buenos Aires: Colihue, 2005.

DUCROT, Oswald. Argumentação retórica e argumentação linguística. Letras de Hoje, Porto Alegre, v. 44, n. 1, p. 20-25, jan./mar. 2009.

DUCROT, Oswald. Polifonía y argumentación. Conferencias del seminario teoría de la argumentación y análisis del discurso. Calli: Universidad del Valle, 1990.

MULLHER, Lucas. Dia Nacional de Combate ao Fumo. [jul. 2012]. Disponível em: <https://www.behance.net/gallery/4567555/Dia-Nacional-de-Combate-ao-Fumo>. Acesso em: ago. 2016

PEIRCE, Charles Sanders. Semiótica. 2. ed. São Paulo: Perspectiva, 2000.

PROPAGANDAS HISTÓRICAS. Cachimbo Bull Dog (Mulher por Perto) - 1969. [s.d.]. Disponível em: <http://www.propagandashistoricas.com.br/2015/01/cachimbo-bulldog-mulheres-por-perto.html>. Acesso em: Ago. 2016.

PROPAGANDAS HISTÓRICAS. Cerveja Malzbier (Beber no Trabalho) - 1967. [s.d.] Disponível em: <http://www.propagandashistoricas.com.br/2013/09/cervejamalzbier-beber-no-trabalho-1967.html>. Acesso em: ago. 2016.

PROPAGANDAS HISTÓRICAS. Volkswagen Fusca (Conversível) - Anos 60. [s.d]. Disponível em: <http://www.propagandashistoricas.com.br/2014/02/volkswagen-fuscaconversivel-anos-60.html>. Acesso em: set. 2016.

PLUGCITÁRIOS. Volkswagen homenageia o cliente. [out. 2013]. Disponível em: <http:// plugcitarios.com/2013/10/01/volkswagen-homenageia-cliente/> Acesso em: set. 2016. 
ROCHA, Simone Maria; SILVA, Vanessa R. de Lacerda e. Publicidade e representações sociais: articulações reveladas pela antipublicidade. INTERCOM - Sociedade Brasileira de Estudos Interdisciplinares da Comunicação, XXX Congresso Brasileiro de Ciências da Comunicação, set. 2007, Santos.

TOLDO, Claudia Stumpf. A relação entre palavra e imagem no texto publicitário: linguagens que argumentam. Letras de hoje, Porto Alegre, v. 37, n. 3, p. 149-162, set. 2002.

ZAMPAR, Silvia. Dia do trabalho e trabalhador. [maio 2012]. Disponível em: <http:// tudibao.com.br/2012/05/dia-do-trabalho-e-trabalhador.html>. Acesso em: ago. 2016.

Recebido em: 30/09/2017

Aceito em: $17 / 01 / 2018$ 